\title{
State and Regional Variation in Prescription- and Payment-Related Promoters of Adherence to Blood Pressure Medication
}

\author{
Peter K. Yang, MPH ${ }^{1,2}$; Matthew D. Ritchey, PT, DPT, OCS, $\mathrm{MPH}^{1}$; Stavros Tsipas, $\mathrm{MA}^{3}$; \\ Fleetwood Loustalot, PhD, FNP ${ }^{1}$; Gregory D. Wozniak, PhD $^{3}$
}

\begin{abstract}
Accessible Version: www.cdc.gov/pcd/issues/2020/19_0440.htm
Suggested citation for this article: Yang PK, Ritchey MD, Tsipas S, Loustalot F, Wozniak GD. State and Regional Variation in Prescription- and Payment-Related Promoters of Adherence to Blood Pressure Medication. Prev Chronic Dis 2020;17:190440. DOI: https://doi.org/10.5888/pcd17.190440.
\end{abstract}

\section{PEER REVIEWED}

\section{SUMMARY}

What is already known on this topic?

Approximately three-fourths of US adults with hypertension do not have their blood pressure controlled. Medication adherence is important in hypertension management and can be affected by how medications are prescribed and purchased.

\section{What is added by this report?}

We found considerable variation in prescription- and payment-related factors that promote medication adherence by geography and across the largest patient market segments comprised of medication prescriber, insurance payer type, and age.

What are the implications for public health practice?

Blood pressure control rates are low and may be affected by uptake of the adherence promotion factors assessed. Increased uptake of these promoters, especially in the regions and populations in most need, could improve hypertension management.

\section{Abstract}

\section{Introduction}

Medication adherence can improve hypertension management. How blood pressure medications are prescribed and purchased can promote or impede adherence.

\section{Methods}

We used comprehensive dispensing data on prescription blood pressure medication from Symphony Health's 2017 Integrated Dataverse to assess how prescription- and payment-related factors that promote medication adherence (ie, fixed-dose combinations, generic formulations, mail order, low-cost or no-copay medications) vary across US states and census regions and across the market segments (grouped by patient age, prescriber type, and payer type) responsible for the greatest number of blood pressure medication fills.

\section{Results}

In 2017, 706.5 million prescriptions for blood pressure medication were filled, accounting for $\$ 29.0$ billion in total spending (17.0\% incurred by patients). As a proportion of all fills, factors that promoted adherence varied by state: fixed-dose combinations (from $5.8 \%$ in Maine to $17.9 \%$ in Mississippi); generic formulations (from $95.2 \%$ in New Jersey to $98.4 \%$ in Minnesota); mail order (from $4.7 \%$ in Rhode Island to $14.5 \%$ in Delaware); and lower or no copayment (from $56.6 \%$ in Utah to $72.8 \%$ in California). Furthermore, mean days' supply per fill (from 43.1 in Arkansas to 63.8 in Maine) and patient spending per therapy year (from $\$ 38$ in Hawaii to $\$ 76$ in Georgia) varied. Concentration of adherence factors differed by market segment. Patients aged 18 to 64 with a primary care physician prescriber and Medicaid coverage had the lowest concentration of fixed-dose combination fills, mean days' supply per fill, and patient spending per therapy year. Patients aged 65 years or older with a primary care physician prescriber and commercial insurance had the highest concentration of fixeddose combinations fills and mail order fills.

\section{Conclusion}

Addressing regional and market segment variation in factors promoting blood pressure medication adherence may increase adherence and improve hypertension management. 


\section{Introduction}

Hypertension is highly prevalent in the United States, affecting almost half of US adults (1). In most cases, hypertension can be effectively managed through lifestyle modification and often with pharmacologic therapy $(2,3)$. However, around three-fourths of US adults with hypertension have blood pressures (BPs) above the thresholds recommended in current guidelines, placing them at increased risk for heart disease and stroke (2).

Medication nonadherence, defined as patients not taking medication as prescribed by their health care provider, is a modifiable barrier to effective management of hypertension and other chronic diseases. Nonadherence increases US health care costs by hundreds of billions of dollars annually (4), often because of the increased risk for cardiovascular events such as myocardial infarction and stroke (4). BP medication nonadherence is highly prevalent and varies by geography and patient demographics $(5,6)$. Multiple prescription- and payment-related factors have been identified that can improve BP medication adherence, thereby increasing the number of patients who achieve a BP goal (7). Prescription-related factors are prescribing fixed-dose combination medications to reduce total pill consumption (8), using mail order prescriptions to address barriers in access to retail pharmacies and to make acquiring prescriptions more convenient for patients (9), and increasing the days' supply per fill to decrease pharmacy visits (10). Payment-related factors to reduce financial barriers are prescribing low-price generic formulations (11), using medications with lower or no patient copayments (12), and minimizing overall out-of-pocket costs for patients (13).

Previous research has described national trends in prescriptionand payment-related factors that promote improved BP medication adherence (14). However, we are unaware of any study assessing state and regional variation in these factors, especially by market segment. Therefore, we used data representing most prescription BP medications filled from US retail and mail order pharmacies in 2017 to describe geographic variation in these adherence promotion factors across the largest market segments (ie, combinations of prescriber type and primary insurance payer type), by patient age group, and by US Census region. These findings can inform strategies to improve BP medication adherence and hypertension control.

\section{Methods}

We obtained prescription fill data through Symphony Health's 2017 Integrated Dataverse (IDV) (15). The IDV contains data on over $90 \%$ of outpatient prescription fills from retail and mail order pharmacies, and combined with market purchasing data, cre- ates national fill and spending estimates. Symphony Health provided data on aggregate number of fills, therapy days, and spending, including total spending and patient spending, for BP medication. These data are presented by 3 patient demographics (age group [18-64 y or $\geq 65 \mathrm{y}$ ], US Census region [northeast, midwest, south, west], and the state the prescription was prescribed in); by 4 prescriber specialties: primary care physicians (PCPs) (includes family practice, internal medicine, and osteopathic medicine], cardiologists, nurse practitioners and physician assistants, and other physician prescribers); 2 pharmacy types (mail order and retail); 2 formulation types (brand and generic); and 4 primary payer types (patient out-of-pocket, commercial insurance, Medicare Part D, and Medicaid). Fills that contained more than one BPlowering medication per pill (ie, fixed-dosed combinations) were counted by the total number of drugs contained when determining the total number of medications filled and total therapy years ( 1 therapy year equals 365 days of available medication) of BP medication dispensed.

Descriptions of adherence promotion factors related to prescriptions and payment used in our study are available elsewhere (14). Briefly, prescription-related factors are the percentage of fills that were for fixed-dose combination, the percentage that were fills by mail order, and the mean number of days' supply per fill, defined as the length of time before a prescription would need to be refilled. Payment-related factors are the percentages of fills for generic formulations and fills with lower or no patient copayment (\$5.00 or less per fill), and patient spending per years' supply of medication (estimated cost of having medication on hand for 365 days). To account for missing values in patient spending $(2.6 \%$ of fills), we calculated patient spending-value means stratified by medication class (eg, $\beta$-blockers) and payer type and applied them to the respective combinations to impute missing values.

Concentration ratios (CRs) were used as a measure of how concentrated a promotion factor was within each market segment (combination of the 4 prescriber types and 4 payer types) and US Census region compared with that observed nationally among all prescribers and payers combined. First, the 3 market segments accounting for the highest number of fills among adults aged 18 to 64 or 65 or older were identified at the national level. CRs were then calculated by dividing the medication adherence promotion factor value observed for those 3 market segments within each region by the value observed nationally. For example, a CR was calculated for the percentage of fills acquired via mail order (an adherence promoter) among patients aged 18 to 64 in the South Census region who had a primary care prescriber and Medicaid

\footnotetext{
The opinions expressed by authors contributing to this journal do not necessarily reflect the opinions of the U.S. Department of Health and Human Services, the Public Health Service, the Centers for Disease Control and Prevention, or the authors' affiliated institutions.
} 
coverage (market segment) divided by the overall percentage of fills acquired via mail order observed nationally. CRs greater than 1.0 imply an overall higher concentration of that factor within that specific market segment and US Census region compared with what is observed nationally among that age group.

Analyses were conducted in SAS version 9.4 (SAS Institute, Inc). The Human Subjects Review Board of the Centers for Disease Control and Prevention (CDC) deemed use of these de-identified, aggregate data exempt from institutional review board review.

\section{Results}

In 2017, 706.5 million BP medication prescriptions were filled, representing approximately $\$ 29.0$ billion in total spending, including $\$ 4.9$ billion in patient spending (Table 1). PCPs were the most frequent prescribers (59.7\% of all fills) and commercial insurance the most frequent payer $(46.0 \%)$. Patients aged 18 to 64 accounted for most fills (52.6\%) and patient spending (51.0\%), although patients aged 65 or older accounted for most total spending $(53.9 \%)$.

Nationally, $11.9 \%$ of all fills were fixed-dose combinations (range, $5.8 \%$ [Maine] to $17.9 \%$ [Mississippi]), $97.4 \%$ were for generic formulations (range, 95.2\% [New Jersey] to 98.4\% [Massachusetts and Minnesota]), 8.6\% were obtained from mail order pharmacies (range, $4.7 \%$ [Rhode Island] to $14.5 \%$ [Delaware]) and $65.9 \%$ had lower or no copayment (range, 56.6\% [Utah] to $72.8 \%$ [California]) (Table 2). On average, 1 year of therapy for a single BP medication cost patients $\$ 50$ out of pocket (range, $\$ 38$ [Hawaii] to $\$ 76$ [Georgia]), and fills had a mean days' supply of 51.3 days (range, 43.1 [Arkansas] to 63.8 [Maine]). Fixed-dose combination fill rates were highest in the South (median, 13.8\% of all fills; range, $10.7 \%$ [Florida] to $17.9 \%$ [Mississippi]) and were the lowest in the Northeast (median, 9.3\% of all fills; range, 5.8\% [Maine and Massachusetts] to $13.2 \%$ [New Jersey]). Generic formulation fill rates were high throughout the country. Use of mail order pharmacies was lowest in the South (median, 8.0\%; range, $5.2 \%$ [Mississippi] to $10.2 \%$ [Virginia]) and highest in the Northeast (median, 9.8\%; range, 4.7\% [Rhode Island] to $14.5 \%$ [Delaware]). The South had the highest percentage of fills with lower or no copayment (median, 65.3\%; range, 61.1\% [Texas] to $70.5 \%$ [Louisiana]). In contrast, patient out-of-pocket spending per therapy year was highest in the South (median, \$51 per therapy year; range, $\$ 43$ [Florida] to $\$ 76$ [Georgia]), driven, at least in part, by the South having the lowest median for mean days' supply per fill (median, 49.9 days; range, 43.1 [Arkansas] to 59.6
[Maryland]). The West had the lowest patient out-of-pocket spending per therapy year (median, \$47; range, \$38 [Hawaii] to $\$ 54$ [Colorado]), and the Northeast had the highest median for mean days' supply per fill (median, 55.8 days; range, 44.7 [Rhode Island] to 63.8 [Maine]).

More than $50 \%$ of all BP medication fills observed nationally were concentrated in the 3 largest market segments (prescriber-payer combinations) for each age group (Table 3 ). Among adults aged 18 to 64 years, the 3 largest market segments were PCPs and commercial insurance $(40.5 \%$ of fills), nurse practitioners and physician assistants and commercial insurance $(11.8 \%)$, and PCPs and Medicaid (8.5\%). Among adults aged 65 or older, the 3 largest market segments were PCPs and Medicare (43.0\% of fills), PCPs and commercial insurance (14.7\%), and cardiologists and Medicare (10.2\%).

CRs for the prescription-related (Figure 1) and payment-related (Figure 2) adherence promotion factors varied by prescriber-payer combination and US Census region. Fixed-dose combination fills tended to be more concentrated, regardless of age, among patients with commercial insurance compared with public insurance (Medicare or Medicaid), especially in the South (Figure 1). The lowest CRs for fixed-dose combination fills were observed among patients aged 18 to 64 with PCP prescribers and Medicaid coverage (CR range, 0.51 [West] to 0.86 [South]) and patients aged 65 or older with cardiologist prescribers and Medicare coverage (CR range, 0.41 [Midwest] to 0.58 [South]). Mail order fills were most concentrated among commercially insured patients aged 18 to 64 with PCP prescribers across all regions (CR range, 1.06 [South] to 2.09 [Northeast]) or with NP or PA prescribers in the Midwest (CR, 1.28) and Northeast (CR, 1.62), and, among commercially insured patients aged 65 or older with PCP prescribers, across all regions (CR range, 1.62 [South] to 2.74 [Midwest]). The lowest mail order concentrations were observed among patients aged 18 to 64 with PCP prescribers and Medicaid coverage (CR range, 0.03 [Northeast] to 0.15 [South]) and among patients aged 65 or older with cardiologist prescribers and Medicare coverage (CR range, 0.46 [Northeast] to 0.83 [Midwest]). Most of the variation in the concentration of days' supply per fill was observed among patients aged 18 to 64 with PCP prescribers and Medicaid coverage (CR range, 0.76 [South] to 0.84 [West]).

The opinions expressed by authors contributing to this journal do not necessarily reflect the opinions of the U.S. Department of Health and Human Services, the Public Health Service, the Centers for Disease Control and Prevention, or the authors' affiliated institutions. 


\section{PREVENTING CHRONIC DISEASE}

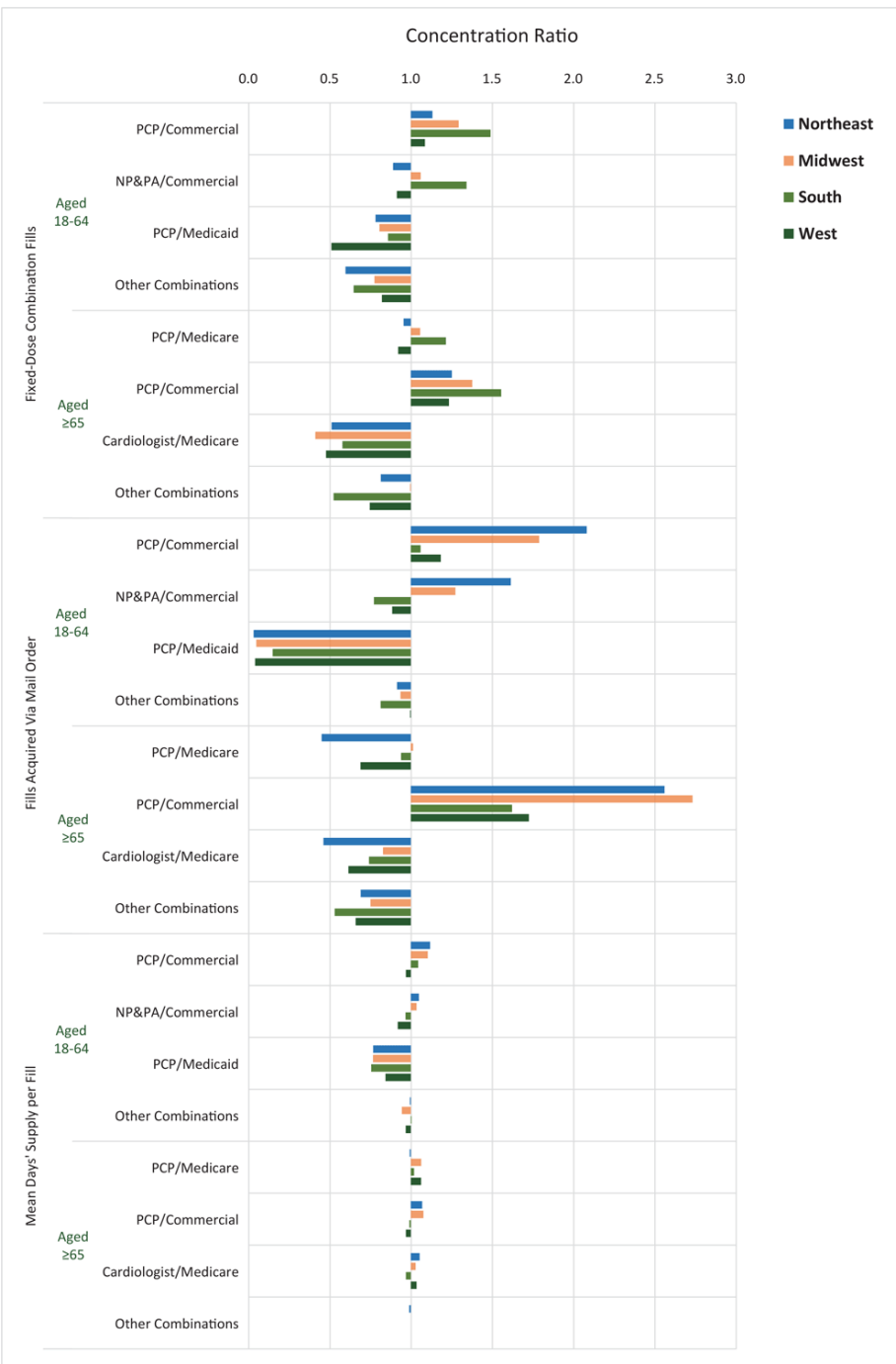

Figure 1. Concentration ratios of adherence promotion factors related to prescriptions among the largest market segments, by US Census region, 2017. Data source: 2017 Symphony Health Integrated Dataverse (15). Abbreviations: NP, nurse practitioner; PA, physician assistant; PCP, primary care physician.

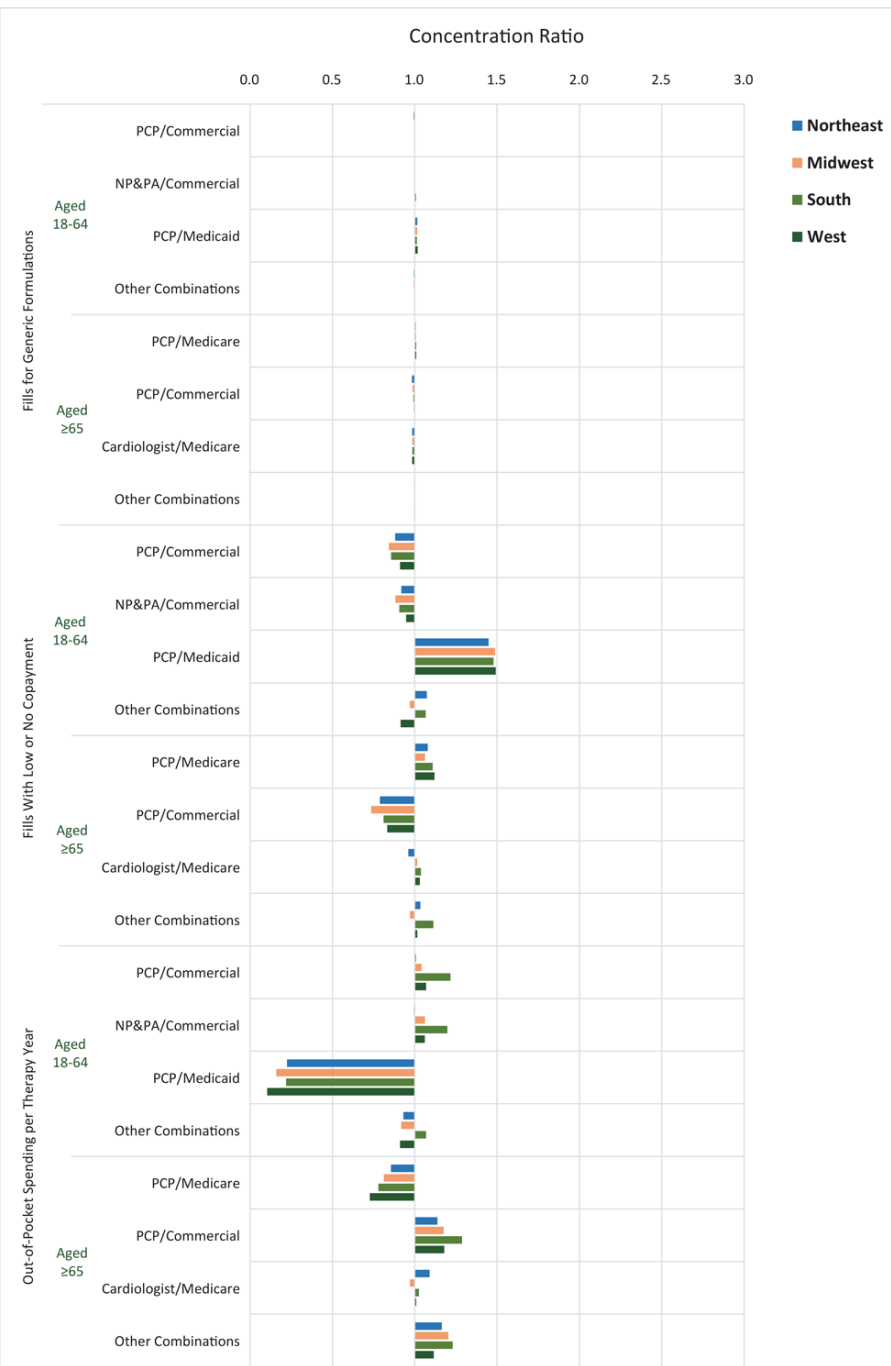

Figure 2. Concentration ratios of adherence promotion factors related to payments among the largest market segments, by US Census region, 2017. Data source: 2017 Symphony Health Integrated Dataverse (15). Abbreviations: NP, nurse practitioner; PA, physician assistant; PCP, primary care physician.

The concentration of fills for generic formulations was similar across all markets and regions for both age groups (Figure 2). The concentration of fills with lower or no copayment among patients aged 18 to 64 was highest among patients with PCP prescribers and Medicaid coverage (CR range, 1.45 [Northeast] to 1.49 [Midwest and West]) and lowest among those with PCP prescribers and commercial coverage (CR range, 0.84 [Midwest] to 0.91 [West]). The group with PCP prescribers and Medicaid coverage also had the lowest concentration of out-of-pocket spending per therapy year (CR range, 0.10 [West] to 0.23 [Northeast]), whereas those

\footnotetext{
The opinions expressed by authors contributing to this journal do not necessarily reflect the opinions of the U.S. Department of Health and Human Services, the Public Health Service, the Centers for Disease Control and Prevention, or the authors' affiliated institutions.
} 
with PCP prescribers and commercial coverage had the highest concentration (CR range, 1.01 [Northeast] to 1.22 [South]). Among patients aged 65 or older, the concentration of fills with lower or no copayment was highest among patients with PCP prescribers and Medicare coverage (CR range, 1.06 [Midwest] to 1.12 [West]) and was lowest among those with PCP prescribers and commercial insurance (CR range, 0.74 [Midwest] to 0.83 [West]). Likewise, patients aged 65 or older with PCP prescribers and Medicare coverage had the lowest concentration of out-of-pocket spending per therapy year (CR range, 0.73 [West] to 0.86 [Northeast]), whereas PCP prescribers and commercial insurance had the highest (CR range, 1.14 [Northeast] to 1.29 [South]).

\section{Discussion}

Despite the 706.5 million BP medication prescription fills that occurred in the United States in 2017, BP medication adherence (16) and BP control rates (17) are low and may be affected by the level of uptake of the adherence promotion factors assessed in this study (18). These factors include modifying how medications are prescribed (ie, prescription-related factors) and by reducing patients' out-of-pocket costs to obtain the medication (ie, payment-related factors). We found considerable variation in these factors by geography and across the largest market segments serving younger and older adults. The opportunity to increase the use of these adherence promoters, especially in the regions and populations in most need, could improve hypertension control, decreasing risk for negative cardiovascular events, including myocardial infarction and stroke.

Evidence suggests that adherence may be affected by how medications are prescribed (8-10). For example, most patients with hypertension require more than 1 medication to control their BP (19). Prescribing fixed-dose combinations for patients taking more than one BP medication has been shown to increase patient adherence by reducing the number of prescriptions they need filled and by decreasing the number of pills they need to take each day (8). However, fixed-dose combinations constituted only $12 \%$ of all national BP medication fills in 2017. Furthermore, the percentage varied considerably by geography and market segment. This includes low concentrations being observed in the South and West - regions with high rates of nonadherence $(20,21)$ - as well as being particularly low among patients aged 18 to 64 years with PCP prescribers and Medicaid coverage. Enrollees in traditional Medicaid more often have a disability, have low income, and have higher rates of chronic disease than similarly aged people with other insurance types (22), and they traditionally have high rates of nonadherence (23). These high rates can be attributed to multiple factors (24), including limited pharmacy access (25), complex drug regimens, and poor refill consolidation (20). Prescribing fixed-dose combination drugs among this population (8), in addition to using other strategies assessed in this study, including use of mail order pharmacies (9) and increasing the days' supply per fill (10), may help address these barriers. Furthermore, evidence suggests that expanding insurance formulary restrictions or tier status of certain medications, such as generic fixed-dose combinations, within preferred drug lists (26) and covering 90-day prescriptions (27) and use of mail order pharmacies (9) can help reduce barriers to adherence. Therefore, state Medicaid programs seeking to improve their rates of BP medication adherence can consider such options. In addition, outreach to prescribers on potential barriers to adherence that Medicaid patients may be at high risk for, and outcomes of incorporating these promoters in prescribing habits, including avenues for groups to use fixed dose combinations, could support these efforts $(28,29)$.

Improving the affordability of medications by addressing payment-related adherence factors is another opportunity to increase adherence among patients with hypertension (11-13). Minimal variation was observed in generic medication concentrations across markets, suggesting that access to these lower cost therapies is widespread. However, there was notable variation in fills with lower or no copayment and out-of-pocket spending per therapy year, especially by payer type and by region. Lower out-ofpocket spending was more concentrated in public insurance markets, especially Medicaid, while higher copayments and out-ofpocket costs were observed among patients with commercial plans, especially in the South where our analysis identified the highest rates of out-of-pocket spending per therapy year among the commercially insured in this region. Higher costs may impose a barrier to adherence, particularly for low-income patient populations for whom even low costs can be prohibitive (13), especially when these costs are compounded by complex medication regimens potentially needed for multiple comorbidities (30). These cost-related factors may be a reason for the low adherence rates seen in the South (31) and, consequently, may play a role in the region's lower BP control rates and higher rates of cardiovascular disease morbidity and mortality than in other census regions (32).

Interventions to address many of the barriers to adherence assessed in this study might require large-scale, collaborative, and long-term quality improvement efforts at multiple levels, including the individual prescriber level $(15,26)$. Health care systems and medical practices could consider incorporating evidence-based strategies that focus on increasing uptake of adherence promotion factors among their prescribers. For example, Kaiser Permanente Northern California improved hypertension control rates by prioritizing generic and fixed-dosed combination drugs as first-line hypertension therapies in their standardized treatment approach (ie, protocol) while using multidisciplinary care teams (19). In Min-

The opinions expressed by authors contributing to this journal do not necessarily reflect the opinions of the U.S. Department of Health and Human Services, the Public Health Service, the Centers for Disease Control and Prevention, or the authors' affiliated institutions. 
neapolis-St Paul, Minnesota, BP control rates improved from around $30 \%$ to around $70 \%$ through collaboration with insurance companies, health care institutions, and government agencies that involved collectively developing and adopting clinical guidelines and shared goals for hypertension treatment (33). Key interventions used in these programs and prescription- and paymentrelated factors highlighted in our study could be replicated and translated into diverse communities to improve BP control. Furthermore, states can work with insurance underwriters (34) to create environments through health insurance market policies with incentives for adherence-promoting prescriptions, like coverage for mail order fills and low copays. Although these measures may lead to higher costs for insurance companies in the short term, they can ultimately lower costs by preventing hospitalizations for expensive acute events (35).

Our study had potential limitations. First, the indications for why medications are being prescribed and whether patients are actually taking the prescriptions they are filling are unknown. If these factors vary by patient demographics or prescriber-payer combinations, it may affect our comparisons across market segments. Second, the cross-sectional nature of this study and the inability to link prescription fill data at the patient level prevents formally establishing relationships between the promotion factors and adherence rates. However, prior studies have described these relationships (7-13). Third, we estimated fills with unknown copay amounts in proportion to fills where copays were known, possibly redistributing fills to incorrect categories. However, the impact was probably minimal because fills with unknown copays represented less than 3\% of fills. Fourth, we might have underestimated patients' average spending per years' supply because our data captured only copayment-related spending and no other patient spending, including drug plan premiums and deductibles. Fifth, misclassification of payment source for some fills may have occurred. For example, fills acquired under Medicare Advantage-associated Part D plans may have been classified as having commercial payment sources and not Medicare Part D, thereby underestimating fills paid for by the latter. Sixth, we are unaware of any study assessing the relationship between the magnitude of the concentration ratios presented in this study and health outcomes. Further analyses are needed to identify meaningful cutpoints that can be applied to these ratios to help identify the market segments in most need of intervention. Finally, IDV data do not account for fills obtained through systems with their own outpatient pharmacies (eg, US Department of Veterans' Affairs, integrated private sector delivery systems, Federally Qualified Health Centers); therefore, regional comparisons may be affected by variation in penetration rates of these systems.
Our study identified considerable variation, by geography and across the largest market segments, in prescription- and paymentrelated factors that promote adherence to BP medication. Future research on the use of adherence promoters by prescribers and payers may identify additional opportunities for interventions. Continued assessment of these data can help evaluate public and private initiatives aimed at addressing these factors in an effort to improve adherence and optimize hypertension management.

\section{Acknowledgments}

Peter K. Yang and Matthew D. Ritchey served as co-first authors and contributed equally to the work. This research was supported in part by an appointment to the Research Participation Program at CDC administered by the Oak Ridge Institute for Science and Education through an interagency agreement between the US Department of Energy and CDC (Peter K. Yang). Peter K. Yang and Matthew D. Ritchey contributed equally to this article. The authors report no conflicts of interest. No study sponsor had any role in the study design, data collection, analysis, or interpretation of data or in writing the article or the decision to submit the article for publication. The findings and conclusions in this report are those of the authors and do not necessarily represent the official positions of CDC or the American Medical Association. No copyrighted materials were used in this article.

\section{Author Information}

Corresponding Author: Peter K. Yang, MPH, Division for Heart Disease and Stroke Prevention, National Center for Chronic Disease Prevention and Health Promotion, Centers for Disease Control and Prevention, 4770 Buford Hwy NE, Mail Stop S107-7, Atlanta, GA 30341. Telephone: 770-498-5260. Email: LZN8@cdc.gov.

Author Affiliations: ${ }^{1}$ Division for Heart Disease and Stroke Prevention, National Center for Chronic Disease Prevention and Health Promotion, Centers for Disease Control and Prevention, Atlanta, Georgia. ${ }^{2}$ Oak Ridge Institute for Science and Education, Oak Ridge, Tennessee. ${ }^{3}$ Improving Health Outcomes Group, American Medical Association, Chicago, Illinois.

\section{References}

1. Benjamin EJ, Blaha MJ, Chiuve SE, Cushman M, Das SR, Deo R, et al.; American Heart Association Statistics Committee and Stroke Statistics Subcommittee. Heart disease and stroke statistics - 2017 update: a report from the American Heart Association. Circulation 2017;135(10):e146-603. Erratum in Circulation 2017;135(10):e646.

\footnotetext{
The opinions expressed by authors contributing to this journal do not necessarily reflect the opinions of the U.S. Department of Health and Human Services, the Public Health Service, the Centers for Disease Control and Prevention, or the authors' affiliated institutions.
} 
2. Whelton PK, Carey RM, Aronow WS, Casey DE, Collins KJ, Himmelfarb CD, et al. Correction to: 2017 ACC/AHA/AAPA/ ABC/ACPM/AGS/APhA/ASH/ASPC/NMA/PCNA guideline for the prevention, detection, evaluation, and management of high blood pressure in adults: a report of the American College of Cardiology/American Heart Association Task Force on Clinical Practice Guidelines. Hypertension 2018;71(6):e140-4.

3. James PA, Oparil S, Carter BL, Cushman WC, DennisonHimmelfarb C, Handler J, et al. 2014 evidence-based guideline for the management of high blood pressure in adults: report from the panel members appointed to the Eighth Joint National Committee (JNC 8). JAMA 2014;311(5):507-20.

4. Munger MA, Van Tassell BW, LaFleur J. Medication nonadherence: an unrecognized cardiovascular risk factor. MedGenMed 2007;9(3):58.

5. Park S, Gillespie C, Baumgardner J, Yang Q, Valderrama AL, Fang J, et al. Modeled state-level estimates of hypertension prevalence and undiagnosed hypertension among US adults during 2013-2015. J Clin Hypertens (Greenwich) 2018; 20(10):1395-410.

6. Ezzati M, Oza S, Danaei G, Murray CJL. Trends and cardiovascular mortality effects of state-level blood pressure and uncontrolled hypertension in the United States. Circulation 2008;117(7):905-14.

7. Gellad WF, Grenard J, McGlynn EA. A review of barriers to medication adherence: a framework for driving policy options. Santa Monica (CA): RAND; 2009.

8. Kawalec P, Holko P, Gawin M, Pilc A. Effectiveness of fixeddose combination therapy in hypertension: systematic review and meta-analysis. Arch Med Sci 2018;14(5):1125-36.

9. Fernandez EV, McDaniel JA, Carroll NV. Examination of the link between medication adherence and use of mail-order pharmacies in chronic disease states. J Manag Care Spec Pharm 2016;22(11):1247-59.

10. Choudhry NK, Fischer MA, Avorn J, Liberman JN, Schneeweiss S, Pakes J, et al. The implications of therapeutic complexity on adherence to cardiovascular medications. Arch Intern Med 2011;171(9):814-22.

11. Shrank WH, Hoang T, Ettner SL, Glassman PA, Nair K, DeLapp D, et al. The implications of choice: prescribing generic or preferred pharmaceuticals improves medication adherence for chronic conditions. Arch Intern Med 2006; 166(3):332-7.

12. Fielding JERB, Rimer BK, Johnson RL, Orleans CT, Calonge N, Clymer JM, et al.; Community Preventive Services Task Force. Recommendation to reduce patients' blood pressure and cholesterol medication costs. Prev Chronic Dis 2015; 12(E209):E209.
13. Njie GJ, Finnie RK, Acharya SD, Jacob V, Proia KK, Hopkins DP, et al.; Community Preventive Services Task Force. Reducing medication costs to prevent cardiovascular disease: a Community Guide systematic review. Prev Chronic Dis 2015; 12:E208.

14. Ritchey M, Tsipas S, Loustalot F, Wozniak G. Use of pharmacy sales data to assess changes in prescription- and payment-related factors that promote adherence to medications commonly used to treat hypertension, 2009 and 2014. PLoS One 2016;11(7):e0159366.

15. SH Solutions. Symphony Health Pharmaceutical Audit Suite PA. (PHAST) 2.0. Conshohocken (PA): Symphony Health Solutions; 2017.

16. Hamdidouche I, Jullien V, Boutouyrie P, Billaud E, Azizi M, Laurent S. Drug adherence in hypertension: from methodological issues to cardiovascular outcomes. J Hypertens 2017;35(6):1133-44.

17. Gillespie CD, Hurvitz KA; Centers for Disease Control and Prevention (CDC). Prevalence of hypertension and controlled hypertension - United States, 2007-2010. MMWR Suppl 2013; 62(3):144-8.

18. Navar-Boggan AM, Pencina MJ, Williams K, Sniderman AD, Peterson ED. Proportion of US adults potentially affected by the 2014 hypertension guideline. JAMA 2014;311(14):1424-9.

19. Jaffe MG, Lee GA, Young JD, Sidney S, Go AS. Improved blood pressure control associated with a large-scale hypertension program. JAMA 2013;310(7):699-705.

20. Ross A, Jami H, Young HA, Katz R. Sync and swim: the impact of medication consolidation on adherence in Medicaid patients. J Prim Care Community Health 2013;4(4):240-4.

21. Chang TE, Ritchey MD, Park S, Chang A, Odom EC, Durthaler $J$, et al. National rates of nonadherence to antihypertensive medications among insured adults with hypertension, 2015. Hypertension 2019;74(6):1324-1332.

22. Chapel JM, Ritchey MD, Zhang D, Wang G. Prevalence and medical costs of chronic diseases among adult Medicaid beneficiaries. Am J Prev Med 2017;53(6,6S2):S143-54.

23. Monane M, Bohn RL, Gurwitz JH, Glynn RJ, Levin R, Avorn J. Compliance with antihypertensive therapy among elderly Medicaid enrollees: the roles of age, gender, and race. Am J Public Health 1996;86(12):1805-8.

24. Cheung PT, Wiler JL, Lowe RA, Ginde AA. National study of barriers to timely primary care and emergency department utilization among Medicaid beneficiaries. Ann Emerg Med 2012;60(1):4-10.e2.

25. Qato DM, Wilder J, Zenk S, Davis A, Makelarski J, Lindau ST. Pharmacy accessibility and cost-related underuse of prescription medications in low-income Black and Hispanic urban communities. J Am Pharm Assoc (2003) 2017; 57(2):162-9.e1. .

The opinions expressed by authors contributing to this journal do not necessarily reflect the opinions of the U.S. Department of Health and Human Services, the Public Health Service, the Centers for Disease Control and Prevention, or the authors' affiliated institutions. 
26. Benjamin IJ, Kreutz R, Olsen MH, Schutte AE, LopezJaramillo P, Frieden TR, et al. Fixed-dose combination antihypertensive medications. Lancet 2019;394(10199):637-8.

27. Ovsag K, Hydery S, Mousa SA. Preferred drug lists: potential impact on healthcare economics. Vasc Health Risk Manag 2008;4(2):403-13.

28. McMenamin SB, Halpin HA, Ibrahim JK, Orleans CT. Physician and enrollee knowledge of Medicaid coverage for tobacco dependence treatments. Am J Prev Med 2004; 26(2):99-104.

29. Reichert S, Simon T, Halm EA. Physicians' attitudes about prescribing and knowledge of the costs of common medications. Arch Intern Med 2000;160(18):2799-803.

30. Mukete BN, Ferdinand KC. Polypharmacy in older adults with hypertension: a comprehensive review. J Clin Hypertens (Greenwich) 2016;18(1):10-8.

31. Ritchey MD, Gillespie C, Wozniak G, Shay CM, ThompsonPaul AM, Loustalot F, et al. Potential need for expanded pharmacologic treatment and lifestyle modification services under the 2017 ACC/AHA Hypertension Guideline. J Clin Hypertens (Greenwich) 2018;20(10):1377-91.

32. Ingram DD, Montresor-Lopez JA. Differences in stroke mortality among adults aged 45 and over: United States, 2010-2013. Atlanta (GA): US Department of Health and Human Services, Centers for Disease Control and Prevention, National Center for Health Statistics; 2015.

33. Foti K, Auerbach J, Magnan S. Improving hypertension control population-wide in Minnesota. J Public Health Manag Pract 2018;24(5):432-9.

34. Kleinke JD. The price of progress: prescription drugs in the health care market. Health Aff (Millwood) 2001;20(5):43-60.

35. Roebuck MC, Liberman JN, Gemmill-Toyama M, Brennan TA. Medication adherence leads to lower health care use and costs despite increased drug spending. Health Aff (Millwood) 2011;30(1):91-9.

The opinions expressed by authors contributing to this journal do not necessarily reflect the opinions of the U.S. Department of Health and Human Services, the Public Health Service, the Centers for Disease Control and Prevention, or the authors' affiliated institutions. 


\section{Tables}

Table 1. Prescription Blood Pressure Medication Fills, Total Spending, and Patient Spending Among Adults Aged 18 Years or Older, by Age Group, Prescriber Type, Payer Type, and US Census Region ${ }^{\mathrm{a}}, 2017$

\begin{tabular}{|c|c|c|c|c|c|c|c|c|c|c|c|c|c|c|c|}
\hline \multirow[b]{3}{*}{ Variable } & \multicolumn{5}{|c|}{ Fills } & \multicolumn{5}{|c|}{ Total Spending } & \multicolumn{5}{|c|}{ Patient Spending } \\
\hline & \multirow[b]{2}{*}{ US } & \multicolumn{4}{|c|}{ US Census Region } & \multirow[b]{2}{*}{ US } & \multicolumn{4}{|c|}{ US Census Region } & \multirow[b]{2}{*}{ US } & \multicolumn{4}{|c|}{ US Census Region } \\
\hline & & NE & MW & s & W & & $\mathrm{NE}$ & MW & s & W & & NE & MW & $s$ & W \\
\hline Total no. ${ }^{\mathrm{b}}$ & 706.5 & 162.1 & 141.4 & 285.8 & 117.2 & 29.0 & 6.0 & 7.0 & 11.6 & 4.4 & 4.9 & 1.0 & 1.1 & 2.1 & 0.7 \\
\hline \multicolumn{16}{|c|}{ Percentage of Total } \\
\hline \multicolumn{16}{|l|}{ Age group, $y$} \\
\hline $18-64$ & 52.6 & 50.0 & 52.2 & 53.7 & 53.6 & 46.1 & 43.8 & 45.8 & 48.0 & 45.0 & 51.0 & 45.9 & 48.9 & 54.8 & 49.8 \\
\hline$\geq 65$ & 47.4 & 50.0 & 47.8 & 46.3 & 46.4 & 53.9 & 56.2 & 54.2 & 52.0 & 55.0 & 49.0 & 54.1 & 51.1 & 45.2 & 50.2 \\
\hline \multicolumn{16}{|l|}{ Prescriber type } \\
\hline $\begin{array}{l}\text { Primary care } \\
\text { physician }^{c}\end{array}$ & 59.7 & 59.1 & 63.2 & 58.7 & 58.3 & 61.2 & 65.4 & 58.5 & 60.8 & 59.2 & 60.3 & 58.3 & 64.4 & 59.7 & 58.7 \\
\hline $\begin{array}{l}\text { Nurse practitioner or } \\
\text { physician assistant }\end{array}$ & 16.3 & 14.6 & 15.3 & 17.1 & 18.1 & 12.8 & 11.3 & 11.9 & 13.6 & 14.3 & 14.4 & 12.5 & 13.8 & 15.4 & 15.4 \\
\hline Cardiologist & 11.9 & 13.8 & 10.6 & 12.1 & 10.8 & 14.8 & 18.2 & 12.4 & 14.6 & 14.3 & 13.8 & 17.3 & 11.6 & 13.5 & 13.3 \\
\hline Other & 12.0 & 12.6 & 10.9 & 12.0 & 12.9 & 11.2 & 12.0 & 10.3 & 11.0 & 12.3 & 11.5 & 11.9 & 10.2 & 11.5 & 12.6 \\
\hline \multicolumn{16}{|l|}{ Payer type } \\
\hline Commercial & 46.0 & 45.5 & 45.4 & 47.3 & 44.0 & 53.8 & 58.1 & 53.5 & 54.2 & 47.7 & 54.1 & 54.0 & 52.9 & 55.6 & 51.7 \\
\hline Medicare & 37.6 & 37.4 & 38.6 & 37.5 & 36.9 & 37.6 & 34.4 & 37.8 & 37.9 & 41.1 & 30.2 & 32.8 & 32.3 & 27.4 & 31.4 \\
\hline Medicaid & 10.9 & 13.4 & 11.1 & 8.0 & 14.6 & 5.0 & 4.9 & 5.5 & 3.7 & 7.6 & 2.4 & 3.0 & 2.4 & 2.0 & 2.8 \\
\hline Patient self-pay & 5.5 & 3.8 & 4.9 & 7.1 & 4.5 & 3.6 & 2.7 & 3.2 & 4.3 & 3.7 & 13.4 & 10.3 & 12.4 & 14.9 & 14.2 \\
\hline
\end{tabular}

Abbreviations: NE, Northeast; MW, Midwest; S, South; US, United States; W, West.

a Data source, 2017 Symphony Health Integrated Dataverse (15).

${ }^{\mathrm{b}}$ Number of fills is in millions and spending is in billions of US dollars.

${ }^{\mathrm{c}}$ Includes family practice, internal medicine, and osteopathic medicine. 
Table 2. Adherence Promoter Values for Blood Pressure Medication, Nationally and by State with Medians by US Census Region, 2017

\begin{tabular}{|c|c|c|c|c|c|c|c|c|c|}
\hline Region & State & $\begin{array}{c}\text { Fixed-Dose } \\
\text { Combination } \\
\text { Fills, \% }\end{array}$ & $\begin{array}{l}\text { Mean No. of } \\
\text { Days' Supply } \\
\text { per Fill }\end{array}$ & $\begin{array}{l}\text { Lower or No } \\
\text { Copayment } \\
\text { Fills, \% }\end{array}$ & $\begin{array}{l}\text { Mail Order } \\
\text { Fills, } \%\end{array}$ & $\begin{array}{l}\text { Generic } \\
\text { Medication } \\
\text { Fills,\% }\end{array}$ & $\begin{array}{c}\text { Patient } \\
\text { Spending, in } \\
\text { Millions, US\$ }\end{array}$ & $\begin{array}{c}\text { Patient } \\
\text { Spending } \\
\text { per Therapy } \\
\text { Year, in } \\
\text { Millions, } \\
\text { US } \$\end{array}$ & $\begin{array}{c}\text { Patient } \\
\text { Spending per } \\
\text { Therapy Year, } \\
\text { in Millions, } \\
\text { US } \$\end{array}$ \\
\hline \multicolumn{2}{|c|}{ United States overall } & 11.9 & 51.3 & 65.9 & 8.6 & 97.4 & $4,926.6$ & 99.4 & 49.6 \\
\hline \multirow{11}{*}{ Northeast } & $\begin{array}{l}\text { Regional } \\
\text { median }\end{array}$ & 9.3 & 55.8 & 64.7 & 9.8 & 97.5 & 41.4 & 0.9 & 46.8 \\
\hline & Connecticut & 10.2 & 55.7 & 67.4 & 8.2 & 96.1 & 61.1 & 1.2 & 49.5 \\
\hline & Delaware & 12.6 & 61.0 & 60.9 & 14.5 & 96.7 & 15.4 & 0.3 & 47.8 \\
\hline & Massachusetts & 5.8 & 52.2 & 67.0 & 9.7 & 98.4 & 106.5 & 2.4 & 43.5 \\
\hline & Maine & 5.8 & 63.8 & 61.6 & 7.4 & 98.3 & 21.6 & 0.5 & 41.3 \\
\hline & $\begin{array}{l}\text { New } \\
\text { Hampshire }\end{array}$ & 6.5 & 55.8 & 61.8 & 12.8 & 97.6 & 21.5 & 0.4 & 48.1 \\
\hline & New Jersey & 13.2 & 56.1 & 61.6 & 12.0 & 95.2 & 174.9 & 3.1 & 56.8 \\
\hline & New York & 11.3 & 49.8 & 69.2 & 8.1 & 96.9 & 303.4 & 6.6 & 46.0 \\
\hline & Pennsylvania & 10.5 & 50.6 & 64.9 & 10.0 & 97.4 & 232.3 & 4.9 & 47.5 \\
\hline & Rhode Island & 8.3 & 44.7 & 71.1 & 4.7 & 98.2 & 19.1 & 0.4 & 44.6 \\
\hline & Vermont & 6.3 & 62.1 & 64.6 & 9.9 & 97.7 & 8.6 & 0.2 & 39.8 \\
\hline \multirow{13}{*}{ Midwest } & $\begin{array}{l}\text { Regional } \\
\text { median }\end{array}$ & 11.4 & 52.5 & 64.5 & 9.4 & 97.5 & 80.3 & 1.8 & 49.1 \\
\hline & lowa & 11.2 & 51.5 & 71.0 & 7.5 & 98.0 & 47.7 & 1.1 & 44.4 \\
\hline & Illinois & 11.8 & 53.2 & 64.7 & 9.3 & 97.4 & 197.1 & 4.0 & 49.2 \\
\hline & Indiana & 13.6 & 51.7 & 61.8 & 12.4 & 97.0 & 122.0 & 2.4 & 51.7 \\
\hline & Kansas & 11.9 & 49.8 & 63.2 & 8.1 & 97.1 & 52.5 & 1.0 & 53.7 \\
\hline & Michigan & 11.6 & 56.8 & 64.4 & 12.8 & 97.6 & 162.2 & 3.7 & 43.3 \\
\hline & Minnesota & 9.6 & 60.2 & 64.3 & 9.4 & 98.4 & 70.7 & 1.6 & 44.4 \\
\hline & Missouri & 10.8 & 49.3 & 65.0 & 9.5 & 97.0 & 110.0 & 2.2 & 49.9 \\
\hline & North Dakota & 10.0 & 53.6 & 58.9 & 6.5 & 98.0 & 13.9 & 0.3 & 54.7 \\
\hline & Nebraska & 12.6 & 48.6 & 64.8 & 7.6 & 96.8 & 33.7 & 0.6 & 57.1 \\
\hline & Ohio & 12.3 & 49.6 & 65.4 & 12.6 & 97.4 & 212.2 & 4.5 & 46.8 \\
\hline & South Dakota & 10.1 & 53.3 & 66.2 & 8.0 & 97.7 & 13.8 & 0.3 & 49.1 \\
\hline & Wisconsin & 10.0 & 60.2 & 62.0 & 11.2 & 97.8 & 89.9 & 1.9 & 46.5 \\
\hline \multirow{8}{*}{ South } & $\begin{array}{l}\text { Regional } \\
\text { median }\end{array}$ & 13.8 & 49.9 & 65.3 & 8.0 & 97.5 & 93.4 & 1.9 & 50.5 \\
\hline & Alabama & 16.0 & 53.6 & 61.2 & 6.0 & 97.5 & 96.2 & 1.9 & 50.1 \\
\hline & Arkansas & 14.5 & 43.1 & 67.5 & 5.9 & 97.6 & 61.3 & 1.1 & 54.3 \\
\hline & $\begin{array}{l}\text { District of } \\
\text { Columbia }\end{array}$ & 12.4 & 49.4 & 70.6 & 5.5 & 97.3 & 9.4 & 0.2 & 49.3 \\
\hline & Florida & 10.7 & 54.9 & 70.0 & 7.6 & 97.8 & 296.1 & 6.8 & 43.4 \\
\hline & Georgia & 14.5 & 47.0 & 64.1 & 5.9 & 97.6 & 243.1 & 3.2 & 76.3 \\
\hline & Kentucky & 11.9 & 44.6 & 69.4 & 8.7 & 97.5 & 87.0 & 1.9 & 46.3 \\
\hline & Louisiana & 14.0 & 44.2 & 70.5 & 8.0 & 97.2 & 96.1 & 1.9 & 50.7 \\
\hline
\end{tabular}


(continued)

Table 2. Adherence Promoter Values for Blood Pressure Medication, Nationally and by State with Medians by US Census Region, 2017

\begin{tabular}{|c|c|c|c|c|c|c|c|c|c|}
\hline Region & State & $\begin{array}{c}\text { Fixed-Dose } \\
\text { Combination } \\
\text { Fills, \% }\end{array}$ & $\begin{array}{l}\text { Mean No. of } \\
\text { Days' Supply } \\
\text { per Fill }\end{array}$ & $\begin{array}{l}\text { Lower or No } \\
\text { Copayment } \\
\text { Fills, \% }\end{array}$ & $\begin{array}{l}\text { Mail Order } \\
\text { Fills, \% }\end{array}$ & $\begin{array}{l}\text { Generic } \\
\text { Medication } \\
\text { Fills,\% }\end{array}$ & $\begin{array}{l}\text { Patient } \\
\text { Spending, in } \\
\text { Millions, US } \$\end{array}$ & $\begin{array}{c}\text { Patient } \\
\text { Spending } \\
\text { per Therapy } \\
\text { Year, in } \\
\text { Millions, } \\
\text { US } \$\end{array}$ & $\begin{array}{c}\text { Patient } \\
\text { Spending per } \\
\text { Therapy Year, } \\
\text { in Millions, } \\
\text { US } \$\end{array}$ \\
\hline & Maryland & 13.7 & 59.6 & 61.3 & 8.8 & 97.2 & 90.6 & 1.8 & 49.8 \\
\hline & Mississippi & 17.9 & 43.4 & 68.1 & 5.2 & 97.5 & 64.4 & 1.1 & 56.7 \\
\hline & North Carolina & 13.9 & 50.4 & 64.9 & 8.7 & 97.6 & 168.0 & 3.3 & 50.3 \\
\hline & Oklahoma & 12.1 & 52.5 & 63.9 & 6.3 & 97.0 & 65.1 & 1.2 & 52.8 \\
\hline & South Carolina & 15.5 & 48.7 & 63.3 & 8.3 & 97.5 & 88.3 & 1.7 & 52.3 \\
\hline & Tennessee & 13.4 & 51.1 & 65.6 & 8.8 & 97.1 & 132.9 & 2.7 & 50.0 \\
\hline & Texas & 15.1 & 52.0 & 61.1 & 8.1 & 96.9 & 431.8 & 7.3 & 59.1 \\
\hline & Virginia & 13.3 & 51.1 & 61.4 & 10.2 & 97.4 & 130.7 & 2.5 & 52.5 \\
\hline & West Virginia & 11.6 & 47.3 & 69.8 & 8.6 & 97.6 & 37.8 & 0.8 & 45.2 \\
\hline \multirow{14}{*}{ West } & $\begin{array}{l}\text { Regional } \\
\text { median }\end{array}$ & 10.8 & 52.7 & 65.1 & 8.1 & 97.9 & 29.8 & 0.6 & 46.6 \\
\hline & Alaska & 11.0 & 59.1 & 64.3 & 8.1 & 95.6 & 8.0 & 0.2 & 51.5 \\
\hline & Arizona & 9.2 & 51.5 & 65.1 & 8.0 & 97.6 & 81.8 & 1.6 & 49.6 \\
\hline & California & 9.4 & 47.9 & 72.8 & 5.3 & 97.8 & 332.8 & 7.5 & 44.3 \\
\hline & Colorado & 11.7 & 53.8 & 59.5 & 10.0 & 97.2 & 52.9 & 1.0 & 53.5 \\
\hline & Hawaii & 12.3 & 60.1 & 61.5 & 6.5 & 98.1 & 12.4 & 0.3 & 38.2 \\
\hline & Idaho & 11.0 & 55.2 & 64.4 & 7.3 & 97.9 & 21.1 & 0.5 & 46.6 \\
\hline & Montana & 9.6 & 52.7 & 66.7 & 8.7 & 98.3 & 14.0 & 0.3 & 45.5 \\
\hline & New Mexico & 10.4 & 50.3 & 68.0 & 8.1 & 98.3 & 22.1 & 0.5 & 45.8 \\
\hline & Nevada & 11.5 & 49.8 & 66.1 & 8.7 & 97.8 & 35.4 & 0.7 & 49.5 \\
\hline & Oregon & 8.4 & 51.5 & 69.5 & 7.0 & 98.1 & 44.8 & 1.1 & 42.5 \\
\hline & Utah & 14.6 & 53.8 & 56.6 & 7.8 & 98.0 & 29.8 & 0.6 & 53.3 \\
\hline & Washington & 8.1 & 50.8 & 68.8 & 8.9 & 97.9 & 73.7 & 1.7 & 42.4 \\
\hline & Wyoming & 10.8 & 54.6 & 58.5 & 9.0 & 97.3 & 8.8 & 0.2 & 58.0 \\
\hline
\end{tabular}

The opinions expressed by authors contributing to this journal do not necessarily reflect the opinions of the U.S. Department of Health and Human Services, the Public Health Service, the Centers for Disease Control and Prevention, or the authors' affiliated institutions. 
Table 3. Prescription Blood Pressure Medication Fill Market Share by Prescriber Type, Payer Type and Patient Age Group ${ }^{\mathrm{a}}, 2017$

\begin{tabular}{|c|c|c|c|c|c|}
\hline \multirow[b]{2}{*}{ Payer and Prescriber Combination } & \multicolumn{2}{|c|}{ 18-64 Years } & \multicolumn{2}{|c|}{$\geq 65$ Years } & \multirow{2}{*}{$\begin{array}{c}\text { All Ages } \\
\text { Market Share, \% }\end{array}$} \\
\hline & Market Share, \% & Top 3 Rank $^{\text {b }}$ & Market Share, \% & Top 3 Rank ${ }^{b}$ & \\
\hline \multicolumn{6}{|c|}{ Commercial insurance } \\
\hline Primary care physician & 40.5 & 1 & 14.7 & 2 & 28.3 \\
\hline Nurse practitioner or physician assistant & 11.8 & 2 & 2.6 & & 7.4 \\
\hline Cardiologist & 6.4 & & 3.9 & & 5.2 \\
\hline Other & 7.8 & & 2.3 & & 5.2 \\
\hline \multicolumn{6}{|c|}{ Medicare } \\
\hline Primary care physician & 5.7 & & 43.0 & 1 & 23.4 \\
\hline Nurse practitioner or physician assistant & 2.1 & & 8.8 & & 5.3 \\
\hline Cardiologist & 1.0 & & 10.2 & 3 & 5.4 \\
\hline Other & 1.6 & & 6.8 & & 4.0 \\
\hline \multicolumn{6}{|c|}{ Medicaid } \\
\hline Primary care physician & 8.5 & 3 & 2.3 & & 5.6 \\
\hline Nurse practitioner or physician assistant & 4.2 & & 0.5 & & 2.5 \\
\hline Cardiologist & 1.3 & & 0.5 & & 0.9 \\
\hline Other & 2.4 & & 0.4 & & 1.5 \\
\hline \multicolumn{6}{|c|}{ Patient self-pay } \\
\hline Primary care physician & 3.8 & & 2.4 & & 3.1 \\
\hline Nurse practitioner or physician assistant & 1.7 & & 0.6 & & 1.2 \\
\hline Cardiologist & 0.5 & & 0.6 & & 0.5 \\
\hline Other & 0.6 & & 0.4 & & 0.6 \\
\hline
\end{tabular}

a Data source: 2017 Symphony Health Integrated Dataverse (15).

${ }^{\mathrm{b}}$ Used to identify the top 3 prescriber and payer combinations (market segments) for each age group to determine the greatest concentration of blood pressure medication fills. 